\title{
Elettaria cardamomum Distillate Increases Cellular Immunity in Doxorubicin Treated Rats
}

\author{
Rikat Raksamiharja ${ }^{1}$, Khairunnisa $\mathrm{Sy}^{1}$, Meirizky Zulharini S. ${ }^{1}$, \\ Annisa Novarina ${ }^{1}$, Ediati Sasmito $^{2 *}$ \\ ${ }^{1}$ Cancer Chemoprevention Research Center Faculty of Pharmacy, Universitas Gadjah Mada, Jalan Sekip Utara \\ 555281 (Phone. 02746492662 Fax. 543120) http://ccrc.farmasi.ugm.ac.id. \\ ${ }^{2}$ Department of Pharmaceutical Chemistry, Faculty of Pharmacy, Universitas Gadjah Mada \\ Jalan Sekip Utara, Yogyakarta 555281, Indonesia
}

\begin{abstract}
Doxorubicin is one of chemotherapeutic agent used for cancer therapy. However, doxorubicin usage causes some adverse effects, such as lymphocyte, CD4+ and CD8+ cells number. Therefore, the co-chemotherapeutic agent is required to reduce the imunosuppression effect. Cardamom (Elettaria cardamomum) contains terpenoid I,8 cineol. This research aimed to know the effect of Elettaria cardamomum distillate (ECD) in combination with doxorubicin on Sprague Dawley rat's hematology profile and the amount of CD4+ and CD8+ cells. The experiment was done for 13 days using 6 groups of rats: I doxorubicin (dox) $15 \mathrm{mg} / \mathrm{kg}$ BW; II dox + ECD $5 \mathrm{mg} / \mathrm{kg}$ BW; III dox + ECD $50 \mathrm{mg} / \mathrm{kg}$ BW; IV dox + ECD $100 \mathrm{mg} / \mathrm{kg}$ BW; V ECD $100 \mathrm{mg} / \mathrm{kg}$ BW; VI control without treatment. The hematology profile and the amount of CD4+ and CD8+ were counted before and after treatment using flowcytometer. The results show that ECD increases the amount of lymphocyte, white blood, CD4+ and CD8+ cells in dose dependent manner in doxorubicin treated rats. Based on the data, it can be concluded that ECD is potential to be developed as immunostimulant agent for chemotherapy.
\end{abstract}

Keywords: Cardamom (Elettaria cardamomum), immunostimulant, hematology, CD4+, CD8+

\section{INTRODUCTION}

Chemotherapy is the treatment method using chemical drugs, remains a first line in the treatment of cancer until now. Doxorubicin, anthracycline antibiotics class has activity against various types of cancer cells and drug of choice in cancer therapy. However, the use of doxorubicin is reported to have side effects included hair loss, sore throat, even cardiotoxicity (Bustova, 2009). In addition, doxorubicin also affects the immune system by decreasing the production of interferon- $\gamma$, natural killer cells (NK), the expression of IL-2, proliferation of lymphocytes, and the ratio of CD4 + / CD8 + (Zhang et al., 2005). Therefore, co-chemotherapeutic agent works synergistically with doxorubicin is needed to counteract the effects of immunosuppression of doxorubicin.

Co-chemotherapeutic agents coming from natural ingredients which can affect the immune system is a prospective. One of the potential plants is cardamom (Elettaria cardamomum). Cardamom contains monoterpenes 1,8-cineol which acts as a chemo-preventive and chemotherapy at the same time (Wattenberg and Morse, 1992) and potential as an agent inducer of apoptosis in cancer cells (Huang et al, 1999). In addition, 1,8-cineol also werereported to stimulate immune response through increased phagocytic ability of macrophages (Serafino et al, 2008).

However, research on the development of Elletaria cardamomum distillate (ECD) is still lacking, previous research is still limited to in vitro studies. In fact not much research to develop the potential of the compound 1,8cineol from ECD as an immunomodulatory agent. Therefore, research is needed on ECD immunomodulatory activities in vivo, particularly as co-chemotherapeutic agent of doxorubicin. This study evaluates effect of cardamomum on immune system based on lymphocyte, $\mathrm{CD} 4+$, and $\mathrm{CD} 8+$ number in vivo.

*Corresponding author e-mail: ediatisasmito@yahoo.com 


\section{MATERIALS AND METHODS}

\section{Plant Collection and Identification}

Cardamomum (Elleteria cardamomum) was obtained from Kapulogo village, Wonosobo, Central Java and was identified at Biology of Pharmacy, Faculty of Pharmacy, Universitas Gadjah Mada. Cardamomum powder was extracted by distillation method for 5 days with aquadest (E.Merck, Darmstadt, Germany). Distillate was collected and $\mathrm{Na}_{2} \mathrm{SO}_{4}$ was added to remove water spots, then filtered and separated.

\section{I,8-cineol Identification using Gas Chromatography}

One mL ECD obtained was injected into the GC injector using a DB-5MS capillary column (dimensions $30 \mathrm{~m} \times 32 \mathrm{~mm}$ ), flow rate $1 \mathrm{~mL} / \mathrm{min}$, split injection, helium carrier gas pressure of $80 \mathrm{kPa}$, injector temperature $250^{\circ} \mathrm{C}$, interface temperature $280{ }^{\circ} \mathrm{C}$, temperature program $60^{\circ} \mathrm{C}$ to $300^{\circ} \mathrm{C} 5$ minutes on hold 2 min (rate of rise of $10^{\circ} \mathrm{C} / \mathrm{min}$ ), with cineol as standard compound. Running of GC carried out in the Laboratorium Penelitian dan Pengujian Terpadu (LPPT) Universitas Gadjah Mada.

\section{Animals}

A total of 30 female Sprague Dawley rats (60days old), weighed from 86 to $112 \mathrm{~g}$ were purchased from Unit Pengembangan Hewan Percobaan Universitas Gadjah Mada. The animals were kept for at least one week before use, and the rats were given standard pellet diet and water ad libitum, and kept on a 12:12 h light/dark cycle.

\section{Experimental Procedure}

Rats were adapted in cages for one week prior to the experiment was treated. Body weight of rats were weighed every day during the experiment to evaluate the condition of the rats, because the rats were stressed or affected by drug side effects may decrease appetite so the weight will be reduced. An effective dose of doxorubicin in this study was $7.5 \mathrm{mg} / \mathrm{kg}$ has been conducted from orientation that can suppress the immune system of rats but did not caused mortality.

Animal tests are grouped into 6 groups, namely doxorubicin treatment group (dox), dox treatment group + ECD dose I, the treatment group dox + ECD dose II, the treatment group dox + ECD dose III, the ECD control group, and the group without treatment. The number of each rat in each group was 6 rats.

a. Group I, the treatment group was given doxorubicin solution at a dose of 7.5 $\mathrm{mg} / \mathrm{kgBW}$ intraperitoneal on first and sixth day.

b. Group II, given doxorubicin at a dose of $7.5 \mathrm{mg} / \mathrm{kg}$ BW intraperitoneal on first and sixth day, and ECD dose of $5 \mathrm{mg} / \mathrm{kg} \mathrm{BW}$ in $1 \%$ CMC-Na solvent were oral every day fromfirst until eleventh day.

c. Group III, given doxorubicin at a dose of $7.5 \mathrm{mg} / \mathrm{kg} \mathrm{BW}$ intraperitoneal on first and sixth day, and ECD dose of $50 \mathrm{mg} / \mathrm{kg} \mathrm{BW}$ in $1 \% \mathrm{CMC}-\mathrm{Na}$ solvent oral every day from first until eleventh day.

d. Group II, given doxorubicin at a dose of $7.5 \mathrm{mg} / \mathrm{kg}$ BW intraperitoneal on first and sixth day, and ECD dose of $100 \mathrm{mg} / \mathrm{kg} \mathrm{BW}$ in $1 \%$ CMC-Na solvent oral every day from first until eleventh day.

e. Group V, as the ECD control group, ECD given at a dose of $100 \mathrm{mg} / \mathrm{kg} \mathrm{BW}$ in $1 \%$ CMC-Na oral every day from first until eleventh day.

f. Group VI, as a group without treatment.

Each rat blood sampled on days 0 and 12 through ocular vein, then hematology profile was analyze with hematology analyzer and CD4+ and CD8+ numbers were measured by using flowcytometry.

\section{Determination of Total Blood Cells Profile with Hematology Analyzer}

Blood samples were taken from test animals and stored in EDTA vacutainer. Furthermore, the number of leukocytes, lymphocytes, neutrophils, and platelets were determined by hematology analyzer. Testing is done with a hematology analyzer at Laboratorium Penelitian dan Pengujian Terpadu (LPPT) Universitas Gadjah Mada.

\section{Determination of Total Lymphocyte CD4+ and CD8+ by Flowcytometry}

Determination of CD4+ and CD8+ count by flowcytometry began by taking blood samples from test animals $3 \mathrm{ml}$ and stored in EDTA Vacutainer. Whole blood sample were prepared and added with reagents. The sample was then read by flowcytometer and analyzed using the MultiSet program with the observed of 15,000 cells population. The data were generated in the form of $\mathrm{CD} 4+$ or $\mathrm{CD} 8+$ count. Testing was done by flowcytometry at 
Biomedical Laboratory of the Faculty of Medicine, Universitas Sebelas Maret Surakarta.

\section{Data Analysis}

The data generated in the form of the number of leukocytes, lymphocytes, neutrophils, and platelets, and lymphocytes CD4+ and CD8+ in the sample. The data obtained were analyzed statistically with the Kolmogorov Smirnov Test to determine the normal distribution. Data were analyzed by one-way ANOVA followed Post Hoc Test and Tuckey test to compare the percentage decrease or increase in blood hematology profile and the number of lymphocytes CD4+ and CD8+ intergroup study with $95 \%$ confidence level.

\section{RESULTS AND DISCUSSION}

\section{The Content of I,8-cineol in ECD Using Gas Chromatography}

Distillate obtained from 300 grams of dried cardamom was as much as $13.5 \mathrm{ml}$. Distillate obtained was colorless, clear, and oily stored in dark glass bottles and in the refrigerator to avoid oxidation process that can damage the distillate. Further test using gas chromatography (GC) was done as a qualitative parameter to determine the compound 1,8cineol contained in the ECD. GC test performed using cineol as standard compound.

Table I. Retention Time and Concentration of Compound in ECD from Gas Chromatography Profile

\begin{tabular}{|c|c|c|c|c|c|}
\hline No & Sample & Peak & $\begin{array}{c}\text { Retention Time } \\
(\text { min) }\end{array}$ & $\begin{array}{c}\text { Concentration } \\
(\%)\end{array}$ & Compound Name \\
\hline \multirow[t]{22}{*}{1} & ECD & $\mathrm{I}$ & 1,279 & 0,206 & - \\
\hline & & 2 & $|, 89|$ & 0,148 & - \\
\hline & & 3 & 1,958 & 0,934 & - \\
\hline & & 4 & 2,108 & 2,855 & - \\
\hline & & 5 & 2,188 & 0,523 & - \\
\hline & & 6 & 2,515 & 33,828 & Cineol \\
\hline & & 7 & 2,704 & 0,154 & - \\
\hline & & 8 & 2,808 & 6,528 & - \\
\hline & & 9 & 3,623 & 2,669 & - \\
\hline & & 10 & 3,783 & 5,783 & - \\
\hline & & 11 & 4,088 & 1,435 & - \\
\hline & & 12 & 4,390 & 0,366 & - \\
\hline & & 13 & 4,532 & 0,071 & - \\
\hline & & 14 & 4,668 & $\mathrm{I}, 073$ & - \\
\hline & & 15 & 4,930 & 0,504 & - \\
\hline & & 16 & 5,587 & 41,715 & - \\
\hline & & 17 & 5,735 & 0,018 & - \\
\hline & & 18 & 6,323 & 0,053 & - \\
\hline & & 19 & 7,223 & $0,07 \mid$ & - \\
\hline & & 20 & 7,856 & 0,848 & - \\
\hline & & 21 & 8,041 & 0,113 & - \\
\hline & & 22 & $|1| 7 \mid$, & 0,104 & - \\
\hline \multirow[t]{2}{*}{2} & Standardcompound & I & $\mathrm{I}, \mathrm{I} 76$ & 0,0 & - \\
\hline & (cineol) & 2 & 2,525 & 0,0 & Cineol \\
\hline
\end{tabular}

Gochev et al., (2012) reported that the main content of the cardamom distillate is 1.8cineol (21-41\%) and $\alpha$ - terpene acetate (21-35 $\%)$. The compound 1,8-cineol is reported to have efficacy to induce apoptosis through fragmentation oligonucleoside (Moteki et al., 2002). This compound is also performs as chemoprevention agent chemotherapy (Wattenberg and Morse, 1992) and capable to stimulate an immune response through increased phagocytic ability of macrophages (Serafino et al., 2008).
ECD Repair Hematology Profile against Immunosupressan Effect of Doxorubicin

In this study, haematology profile such as leukocytes, lymphocytes, neutrophils, and platelets were observed in rats treated with doxorubicin and ECD (Fig.1). Based on the results of the statistical test is known that there are significant differences in the number of leukocytes, lymphocytes, and platelets each treatment group compared with untreated group. The results of this study indicate that treatment with ECD at $100 \mathrm{mg} / \mathrm{Kg} \mathrm{BW}$ did not decrease the number of cells in hematology 
profile, but intended to increase the number of leukocytes, lymphocytes, and neutrophils. It is seen from the data the percentage of blood component number of ECD treated group at
$100 \mathrm{mg} / \mathrm{Kg} \mathrm{BW}$ which was always positive and not significantly different compared with the untreated controls.

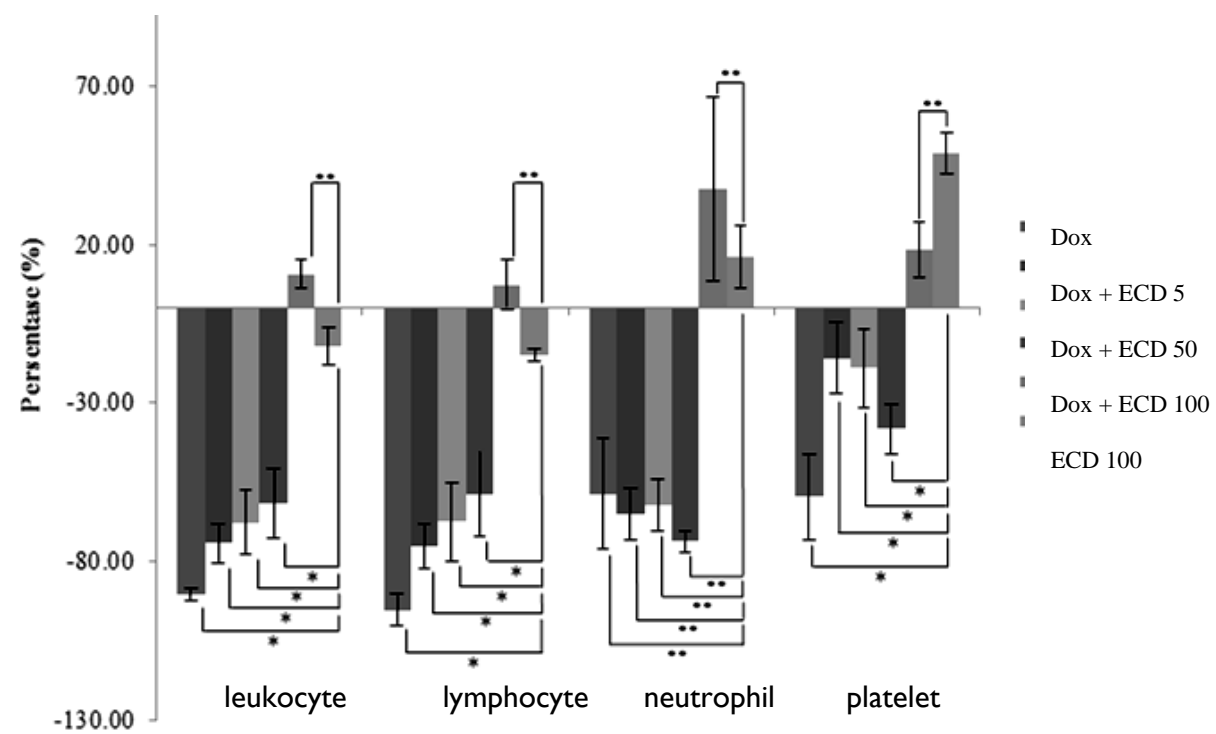

Figure I. ECD Repair Hematology Profile against Immunosupressan Effect of Doxorubicin. Sprague dawley rat was given with doxorubicin and ECD for II days and the blood sample was taken and analyzed with haematology analyzer as described in the methods. The negative sign indicates a decrease. $\left(^{*}\right)$ Indicates data was significantly different $(p<0.05)$. (**) Indicates the data was not significantly different $(p<0.05)$. Whole bloods from each group were analyzing using hematology analyzer. Changes in the number of leukocytes, lymphocytes, neutrophils, and platelets were tested using one-way ANOVA with $95 \%$ confidence level.

Cancer therapy using doxorubicin caused side effects including cell resistance, cardiotoxicity and decreased immune system. The suppression of immune system will lead to patient susceptible to infections and other diseases (Patel et al., 2007). Previous study from Zhang et al. (2005) showed that doxorubicin inhibits lymphocyte proliferation and decrease the number of leukocytes as the result. Doxorubicin can cause DNA damage in cells of the spinal cord (Uspenskaya et al., 2004), leading to suppression of immune cells. Doxorubicin is cytotoxic to cells which are actively divided. Bone marrow cells that are the origin of blood cells are cells that have the ability to continue to divide. Therefore, it is certain that the reduction in the number of leukocytes, lymphocytes, neutrophils, and platelets in the doxorubicin group.

\section{ECD Improve Specific Immune State through Increased the Number of CD4+ and CD8+}

There are 3 types of differentiation of lymphoid pathway namely B lymphocytes, $\mathrm{T}$ lymphocytes, and natural killer cells. Lymphocytes are the specific immune system which has activities in the fight against cancer cells. In this study, cardamom distillate expected has potency to increase the number of leukocytes and lymphocytes. It is possible that the cardamom distillate has action to improve the immune system by increasing the specific immune system. To know the state of the specific immune system, the study was conducted determination of the number of lymphocytes CD4+ and CD8+. 


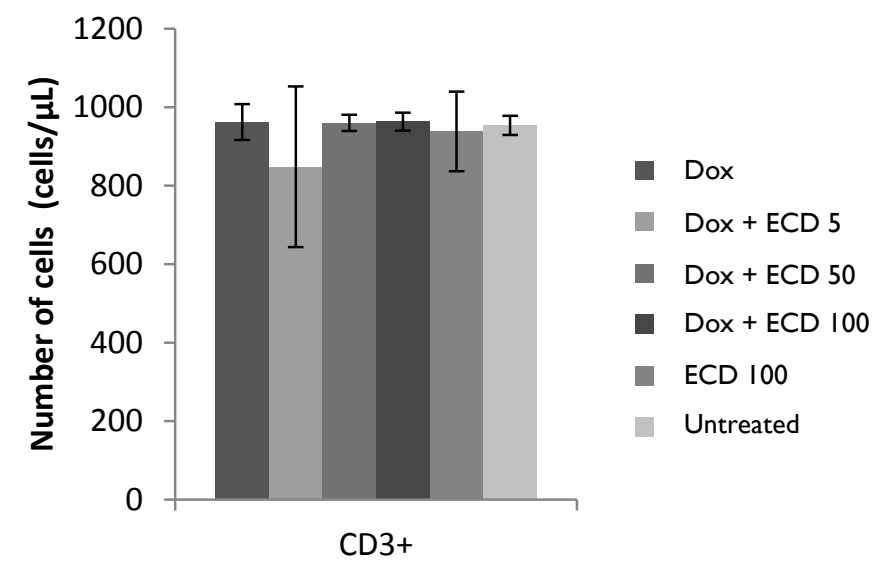

(A)

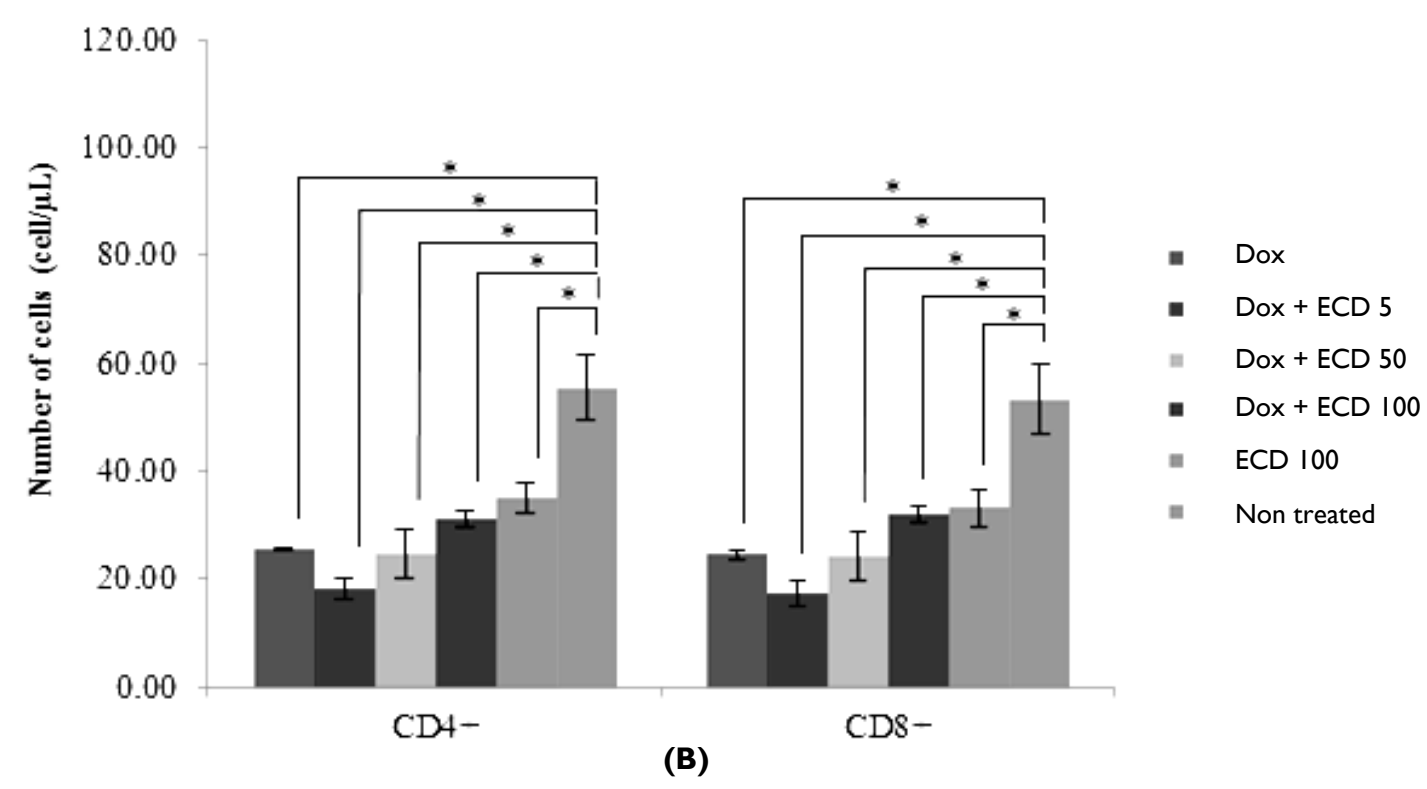

Figure 2. ECD Improve Specific Immune State through Increased the Number of CD+3, CD+4 and $C D+8$. Sprague dawley rat was given with doxorubicin and ECD for II days, and the blood sample was taken and subjected for flowcytometry analysis as described in the methods. The data showed that ECD tend to increase number of $C D+3$ (a), $C D+4$ and $C D+8$ lymphocyte cells (b). (*) Indicates data was significantly different (p<0.05). (**) Indicates the data was not significantly different $(p<0.05)$.

ECD control group at dose $100 \mathrm{mg} / \mathrm{Kg}$ $\mathrm{BW}$ tend to reduce the number of lymphocytes $\mathrm{CD} 4+$ and $\mathrm{CD} 8+$ compare to untreated group. Doxorubicin group also experienced a significant decrease when compared to the untreated control group in the number of lymphocytes $\mathrm{CD} 4+$ and $\mathrm{CD} 8+$. ECD treatment dose of $5 \mathrm{mg} / \mathrm{Kg} \mathrm{BW}, 50 \mathrm{mg} / \mathrm{Kg} \mathrm{BW}$ and 100 $\mathrm{mg} / \mathrm{Kg}$ BW combination with doxorubicin 7.5 $\mathrm{mg} / \mathrm{kg}$ body weight showed there is no improvement of lymphocytes CD4+ and CD8+ profile significantly. This shows the inability of ECD at dose $5 \mathrm{mg} / \mathrm{Kg} \mathrm{BW}, 50 \mathrm{mg} / \mathrm{Kg} \mathrm{BW}$ and $100 \mathrm{mg} / \mathrm{Kg}$ BW to improve specific immune system due to a decrease in the side effects of chemotherapy agent doxorubicin.

Compound 1,8-cineol performs antiinflammatory activity through the inhibition mechanism of the expression of proinflammatory cytokines (IL-1 $\beta$, IL- 6 and TNF$\alpha$ ), COX-2, and activation of NF- $\kappa \mathrm{B}$ (Cho , 2013). In cases of acute inflammatory, role of TNF- $\alpha$ and other proinflammatory cytokines is very beneficial for the body homeostatic. However, it's different with the case of chronic inflammatory diseases, for example cancer. 
Chronic inflammation can occur due to persistent antigens in tissues, causing an immune response of the body that continuously triggers the secretion of pro-inflammatory cytokines. According to Aggarwal et al. (2006), it can even be linked to all stages of the process of carcinogenesis, including cellular transformation, proliferation, invasion, angiogenesis, and metastasis. Therefore it can be expected role of the compound 1,8-cineol in cardamom distillate as an anti -inflammatory activity can suppress the activity of TNF- $\alpha$ as an endogenous tumor promoter to suppress the development of cancer cells.

Majdalawieh and Carr (2010) states that cardamom distillate can increase the cytotoxic activity of natural killer cells. Natural killer cell has cytotoxic role as the first defense of immune system. Natural killer cells and lymphocytes formation through lymphoid pathway, but natural killer cells doesn't have specific receptors to recognize the target. Natural killer cells are very effective in attacking the target cells because it can change quickly without going through the process of genetic structuring like $\mathrm{B}$ cells and $\mathrm{T}$ cells (Jakobisiak et al., 2003). Highactivity of natural killer cell could be one of the parameters of the ability of anti-cancer agents through increased immune system. In the study Hassan et al (2010) reported that the $\alpha$-terpineol, which is one component of the cardamom distillate have activity as potential anti-cancer agents by inhibiting NF- $\mathrm{NB}$ pathway. These indicate cardamom distillate also has the potential to be used as an anti-cancer agent than as immunostimulant agents.

Treatment with ECD improve the state of the immune cells through the increase in the number of leukocytes, lymphocytes, and neutrophils, but have not been able to repair a decrease in the number of lymphocytes CD4+ and CD8+ in female Sprague Dawley rats after doxorubicin chemotherapy. Further research is needed to investigate activity of ECD in other immune mechanism.

\section{ACKNOWLEDGEMENT}

We acknowledge Directorate General of Higher Education, Ministry of Education and Culture, Republic of Indonesia who has funded this research in 2011.

\section{REFERENCES}

Aggarwal, B.B., Shishodia, S., Sandur, S.K., Pandey, M.K. and Sethi, G., 2006, Inflammation and cancer: how hot is the link?, Biochem. Pharmacol., 72(II), |605-|62|.

Bustova, I., 2009, Risk of Cardiotoxicity of Combination Treatment Radiotherapy and Chemotherapy of Locally Advanced Breast Carcinoma Stage III. Klin Onkol., 22(I), I7-2I.

Cho, K.H., 2012, I,8 Cineole Protected Human Lipoproteins from Modification by Oxidation and Glycation and Exhibited Serum Lipid-Lowering and AntiInflammatory Activity in Zebafish, $B M B$ Rep., 45, 565-570.

Gochev, V., Girova, T., Stoilova, I., Atanasova, T., Nenov, N., Stanchev, V. and Soyanova, A., 2012, Low temperature extraction of essential oil bearing plants by liquefied gases. 7. Seeds from cardamom (Elettaria cardamomum (L.) Maton), J. BioSci. Biotech., I(2), I35139.

Hassan, S.B., Muhtasib H.G., Goransson, H. and Larsson, R., 2010, Alpha Terpineol: A Potential Anticancer Agent which Acts through Suppressing NF- $\mathrm{B}$ Signalling, Anticancer Research, 30, 1911-1920.

Huang, Y., Fang, J., Hung, C., Wu, P. and Tsai, Y., 1999, Cyclic monoterpene extract from cardamom oil as a skin permeation enhancer for indomethacin: in vitro and in vivo studies, Biol Pharm Bull., 22, 642-646.

Jakóbisiak, M., Lasek, W., and Gołab, J., 2003, Natural mechanisms protecting against cancer, Immunol Lett., 90(2-3), 103-22.

Majdalawieh, A.F. and Carr, R.I., 2010, In vitro investigation of the potential immunomodulatory and anti-cancer activities of black pepper (Piper nigrum) and cardamom (Elettaria cardamomum), J Med Food, I3(2), 37I-38I.

Moteki, H., Hibasami, H., Yamada, Y., Katsuzaki, H., Imai, K. and Komiya, T., 2002, Specific induction of apoptosis by I,8-cineole in two human leukemia cell lines, but not a in human stomach cancer cell line. Oncol Rep., 9, 757-760.

Patel, D., Shukla, S. and Gupta, 2007, Apigenin and Cancer Chemoprevention: 
Progress, Potential, Promise (Review), International Journal of Oncology, 30, 233-245.

Serafino, A., Vallebona, P.S., Andreola, F., Zonfrillo, M., Mercuru, L., Federici, M., Rasi, G., Garaci, E. and Pierimarchi, P., 2008, Stimulatory effect of Eucaliptus essential oil on inante cell-mediated immune response, BMC Immunol., 9, 17.

Uspenskaya, Y.A., Mikhutkina, S.V.,. Taksanova, E.I., Popova, N.N., Olovyannikova, R.Y. and A.B. Salmina, 2004, Induction of Apoptosis in Bone Marrow Cells is
Mediated via Purinergic Receptors, Bull Exp Biol Med., I 38(2), I |4- I I8.

Wattenberg, L., 1992, Inhibition of carcinogenesis by minor dietary constituents. Cancer Res., 52, 2085209l.

Zhang, Xiao-Yu, Li, Wen-Guang, Wu, Yong-Jie, and Gao, Ming-Tang, 2005, Amelioration of Doxorubicin-Induced Myocardial Oxidative Stress and Immuosuppression by Grape Seed Proanthocyanidins in Tumour-bearing Mice, Journal of Pharmacy and Pharmacology, Pharmaceutical Press, 57(8), $|043-105|$. 